\title{
ANALISIS ASOSIASI KULTURAL ATAS WARNA
}

\author{
Mita Purbasari; Laura Christina Luzar; Yusaira Farhia \\ Visual Communication Design, School of Design, BINUS University \\ Jln. K.H. Syahdan No. 9, Palmerah, Jakarta Barat 11480 \\ mitawahid@binus.edu, lluzar@binus.edu, pleasedehra@yahoo.com
}

\begin{abstract}
Cultural association analysis of color is an approach to know color from the side of culture. Unlike the previous color studies which see the color from the aspect of psychology, this research of color aims to provide insight based on the colors from local culture. Johannes Itten's theory of color was used as a basis of thought in this research. The theory was reflected to Indonesian cultures, and this time, represented by Java island. Research used qualitative method by literature study, interviewing the color experts, historians and artists, visiting cultural centers. Results of the research are in the form of morphological matrix cultural over color. Matrix of analysis resulted in argument and study proposal. Students implemented the color schemes from 5 big cities in Java. They were asked to change the color composition of food and beverage packaging. Students may use, explore, and maximize the principle of color in visual communication to achieve contrast and balance.
\end{abstract}

Keywords: cultural assosiastion, color

\begin{abstract}
ABSTRAK
Analisis asosiasi kultural atas warna merupakan sebuah pendekatan untuk mengenal warna dari sisi kultural/budaya. Tidak seperti penelitian-penelitian warna sebelumnya, yang melihat warna dari aspek psikologi, penelitian warna kali ini bertujuan untuk memberikan wawasan warna-warna lokal berdasarkan kultural. Teori pakar warna Johannes Itten digunakan sebagai dasar pemikiran dalam penelitian kali ini. Teori tersebut akan direfleksikan ke budaya Indonesia, yang kali ini diwakili oleh Jawa. Metode penelitian kualitatif meliputi pengumpulan data berupa studi literatur, wawancara para ahli warna, sejarawan dan budayawan, mengunjugi pusat-pusat kebudayaan. Hasil penelitian berupa morphological matrix kultural atas warna. Matrix analisis ini menghasilkan proposal argumen dan studi. Mahasiswa menerapkan skema warna dari 5 kota di pulau Jawa. Mereka diminta untuk mengubah komposisi warna dari kemasan makanan atau minuman. Mahasiswa dapat menggunakan, mengolah, dan memaksimalkan kaidah warna dalam komunikasi visual untuk mencapai kontras dan balance.
\end{abstract}

Kata kunci: asosiasi kultural, warna 


\section{PENDAHULUAN}

Pendidikan desain komunikasi visual (DKV) sedang berlomba tumbuh besar di Indonesia, khususnya di Jakarta. Hampir semua lembaga pendidikan baik yang berjenjang sarjana, diploma, maupun sertifikat membuka peluang bagi masyarakat untuk mengenyam ilmu DKV. Dapat dikatakan pendidikan DKV sedang naik daun. Bahkan lembaga pendidikan Indonesia harus berjuang keras melawan persaingan lembaga-lembaga pendidikan asing yang tumbuh makin banyak dan mapan.

Walaupun keilmuan DKV -yang dulu dikenal dengan Desain Grafis- sudah ada sejak awal 70'an di Indonesia dan terus berkembang peminatnya, pengertian akan keilmuannya sendiri masih sangat bias. Hal itu terjadi tidak hanya di kalangan orangtua calon mahasiswa tetapi juga di antara anak muda sebagai calon mahasiswa. Beberapa alasan calon mahasiswa memilih jurusan DKV karena dianggap jauh dari matematika, DKV sedang menjadi tren, menjadi gaya hidup anak muda sekarang, juga daripada tidak kuliah. Sedangkan di pemikiran para orangtua calon mahasiswa, DKV menetaskan insan seniman yang dianggap tidak jelas masa depannya. Pada kenyataannya di lapangan perkuliahan, menjadi anggota keluarga mahasiswa DKV bukanlah pekerjaan yang mudah. Diperlukan stamina jasmani dan rohani yang kuat, stabil, dan sehat agar mampu memahami dan mengerti keilmuan DKV sehingga dapat menyelesaikan masa studinya dengan baik dan diterima di masyarakat dan industri.

Alasan-alasan tersebut tidak membuat pendidik dan pengajar keilmuan DKV patah semangat, tetapi memicu semangat untuk memberikan yang terbaik bagi anak-anak didik. Sehingga mereka mampu menentukan sikap dan pilihan sendiri, kemudian berhasil mengemban ilmu dan diterima di masyarakat. Untuk menarik perhatian dan minat masyarakat yang tepat akan keilmuan DKV pada umumnya dan DKV Binus University pada khususnya, maka sebagai pengajar dan pendidik di DKV Binus University perlu sebuah pemikiran yang fokus terhadap kurikulum dan materi ajar agar memiliki ciri khas yang unik sehingga menarik minat masyarakat dengan tepat. Pendidikan dasar yang kuat akan memudahkan mahasiswa untuk terus berkembang hingga akhir.

Sebagai pengajar dan pendidik mahasiswa di DKV Binus University pada pendidikan dasar (Nirmana, Teori Warna, dan DKV 1), sesuai dengan fokus pendidikan di DKV Binus berbasis local content, maka proyek kelas pendidikan dasar Teori Warna ingin dibawa sebagai bahan penelitian. Mata kuliah ini menjadi pendidikan fondasi bagi beberapa mata kuliah terkait, seperti Nirmana Dasar, Tipografi 1-3, Komputer Grafis 1-2, DKV 1-5. Begitu banyak dan seringnya warna digunakan dalam kehidupan sehari-hari, terutama dalam keilmuan DKV. Kemampuan untuk mempersepsikan warna merupakan dasar dari banyak aktivitas pembuatan dan penggunaan tanda di seluruh dunia.

Salah satu materi ajar dalam mata kuliah Teori Warna membahas tentang teori warna dasar dari para ahli, seperti teori warna van Goethe, Johannes Itten, Munsell, dan Oswald. Materi ini diberikan agar mahasiswa memahami betul proses pembentukan warna yang sekarang mereka banyak gunakan dalam dunia digital. Dari nama-nama penemu teori warna yang diberikan di kelas, peneliti memilih teori Johannes Itten sebagai dasar awal penelitian ini. DKV Binus sebagai lembaga pendidikan keilmuan yang berbasis ajaran Bauhaus, mengacu pada Johannes Itten sebagai dasar keilmuan warna dalam penelitian ini.

Johannes Itten seorang artis berasal dari Swiss yang melebarkan teori warna Isac Newton dan pakar lainnya dalam pengembangan teori warnanya sendiri. Itten mengembangkan konsep rona warna (Concept of Color Cords), sesuai dengan Color Wheel Pro.com. Itten juga memodifikasi lingkaran warna yang dimasukan ke sistem komputer. Teori warna Itten memperhitungkan tidak hanya warna kontras tetapi juga efek emosionalnya. Karya pertamanya dikembangkan di School of Applied Arts "Bauhaus", Weimar (sekolah desain terkenal di Jerman, tempat Itten mengajar), dan selanjutnya para seniman dan desainer terus merujuk dan menggunakan teori warnanya hingga kini. 
Berdasarkan 3 warna primer merah, kuning, dan biru, Itten memperbarui lingkaran warna yang sudah ada, dan menghasilkan 12 warna dalam lingkaran warnanya. Itten mengembangkan teori umum kontras, tema utama yang merupakan "kontras bias / kabur", sebagai dasar untuk materi ajarnya. Selain teori kontras, Itten mengembangkan teori saturasi dan hue (warna). Pendekatan struktural studi Itten didasarkan pada kontras terang-gelap, kontras dingin-hangat, dan kontras komplementer dan simultan. Upaya Itten mencapai produksi yang mencakup semua artistik. Itten tidak hanya membatasi diri untuk melihat warna secara ilmiah, bereksperimen dengan gelombang cahaya dan refleksi, perspektif para penggunanya, menjelajahi hubungan tiap warna dan efek visualnya, tetapi Itten juga yakin bahwa warna memiliki efek psikologi dan spiritual kepada manusia dan memengaruhi cara manusia merasakannya.

Sesuai dengan tujuan utama pembelajaran materi Teori Warna, yaitu agar mahasiswa dapat membuat kombinasi warna dengan bermain hue, tints dan shades. Dasar teori warna Itten dapat digunakan untuk semua aspek kehidupan. Karena secara eksplisit (rona/rupa) dan implisit (makna/arti), manusia di dunia ini menggunakan warna dalam segala bentuk dan tujuan.

Seperti halnya komponen visual lainnya, warna dapat membantu untuk menciptakan makna. Dibandingkan dengan elemen desain lainnya, warna memiliki kemampuan untuk membuat seorang menyadari yang dilihat, untuk segala sesuatu yang tidak memiliki arti tanpa menggunakan warna. Menggunakan warna dalam mendesain karya menjadi bagian terpenting bagi seorang desainer, baik itu desainer grafis, interior, produk, bahkan untuk seorang arsitek dan seniman. Sama halnya dengan manusia, warna pun perlu nama untuk mengidentifikasikannya, sesuai dengan karakter, sifat, dan citra yang ditimbulkannya.

Sebagai pengajar dan pengamat warna, masalah asosiasi warna di negeri ini menjadi salah satu pengamatan penulis yang cukup mendalam. Dengan warna seorang dapat berkomunikasi secara visual dengan baik tanpa harus menggunakan tulisan dan kata-kata. Warna dapat berbicara dan menjadi media pemecah masalah dalam berkomunikasi. Surat dan bunga mawar berwarna merah muda dapat dengan cepat ditangkap sebagai ungkapan perasaan cinta atau kasih sayang. Hal seperti ini berlaku universal.

Warna juga dapat digunakan untuk menggambarkan hal-hal seperti apa adanya, misalnya warna hijau dari rumput di suatu daerah setempat. Warna juga dapat digunakan tanpa referensi objek yang diamati untuk menghubungkan manusia ke suatu hal yang lebih abstrak atau makna simbolik. Warna juga dapat digunakan untuk menyampaikan suasana, perasaan, atmosfer. Warna secara konotatif memiliki nilai simbolis yang spesifik menurut budaya. Contohnya, dalam budaya Indonesia, kuning berkonotasi sifat pengecut, di Cina konotasinya adalah kerajaan.

Meskipun daya terima manusia terhadap reaksi warna hampir sama, tiap manusia memiliki interprestasi yang berbeda dari makna warna. Sebagian besar sifat warna dipahami dalam hubungannya dengan lingkungan, tempat mereka berada dan ditafsirkan melalui pengamat dan pengguna warna. Beberapa warna mengandung makna yang sama di budaya yang berbeda, misalnya dan beberapa warna yang sama memiliki makna yang berbeda di budaya mirip.

Pengelompokan warna dapat dilakukan melalui beberapa hal, antara lain: objek, psikologi, lingkungan (natural environment), organisasi, dan lainnya. Penelitian kali ini dilakukan berdasarkan budaya. Hal ini disebabkan karena beberapa hal, yaitu kurangnya hasil penelitian warna berdasarkan aspek budaya (paling banyak berdasarkan aspek psikologi), kurangnya perhatian dari pemerintah Republik Indonesia terhadap seni dan budaya sementara Indonesia kaya akan keragaman budaya, dan minimnya pengetahuan anak-anak muda Indonesia masa kini mengenai kekuatan budayanya sendiri.

Berdasarkan alasan-alasan tersebut, peneliti memandang perlu adanya penelitian warna berdasarkan kultural, khususnya Indonesia yang hasilnya berupa berupa morphological matrix culture 
atas warna yang dapat digunakan untuk banyak kepentingan. Warna yang akan digunakan adalah 6 warna pokok yang ada di lingkaran warna Itten (merah, kuning, biru, hijau, jingga, dan ungu) ditambah dengan warna netral (hitam, putih, dan abu-abu). Penelitian kali ini hanya berfokus di kotakota besar pulau Jawa saja, dan tidak menutup kemungkinan akan diteruskan ke pulau-pulau besar lainnya dalam penelitian berikutnya.

\section{METODE}

Classroom research menggunakan metode kualitatif deduksi dengan teori dasar warna Johannes Itten sebagai basisnya (digunakan dalam materi ajar mata kuliah teori warna). Kemudian berdasarkan teori tersebut, dilihat hubungan teori Itten dengan penerapan warna di masyarakat kotakota besar di Indonesia, khususnya masalah budaya.

Sebelum memulai pada tahap penelitian, peneliti membuat pengelompokan warna dasar yang akan diteliti. Sesuai dengan 12 warna dalam lingkaran warna Johannes Itten, peneliti menetapkan hanya menggunakan warna 3 warna primer (merah, kuning, biru) dan 3 warna sekunder (jingga, hijau, ungu), ditambah dengan 3 warna netral (hitam, abu-abu, putih). Hal ini disebabkan warna primer, sekunder, dan netral sudah biasa diterima dan ditangkap oleh mata manusia. Selanjutnya peneliti mendokumentasikan objek-objek yang memiliki warna khas/dominan, sesuai dengan kelompok warna yang telah ditentukan tadi.

Beberapa tahap yang akan dilakukan peneliti dalam pelaksanaannya adalah sebagai berikut. Pertama, objek formal penelitian, yaitu fenomena warna sebagaimana dipandang dari model warna Johannes Itten dengan studi literatur formal objek, taksonomi/morfologi, dan analisis/klasifikasi sebagai morfologi proses kreasi di kelas. Kedua, objek material penelitian, yaitu spektrum warna di pulau Jawa yang dapat diobeservasi berbasis model warna Johannes Itten dengan observasi warnawarna di pulau Jawa dan praktik di kelas/studio. Diagram berikut menunjukkan tahapan metode penelitian.

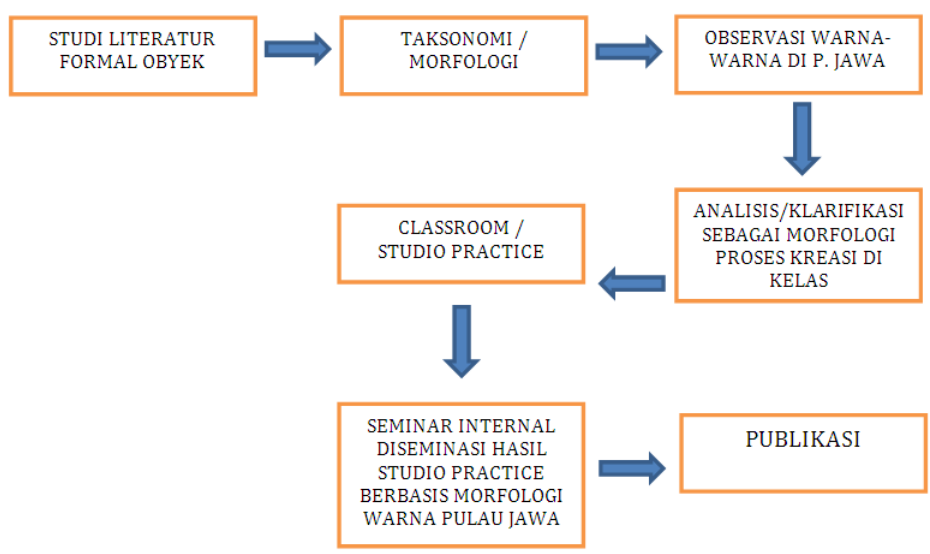

Gambar 1 Tahapan Metode Penelitian

\section{HASIL DAN PEMBAHASAN}

Penggunaan teknologi digital saat ini sangat berperan dalam kehidupan, termasuk dalam aspek dunia desain komunikasi visual. Kamera dan komputer dalam desain komunikasi visual ini mencakup efisiensi baik dari proses pekerjaan sampai pada pelestarian karya desain. Warna sebagai salah satu 
media dan elemen desain yang cukup penting karena tidak hanya memberikan nilai estetis, keseimbangan, tetapi juga mengantarkan suatu pesan baik secara denotatif (nyata) maupun konotatif (implisit).

Dalam mencari dan menggunakan warna, cara terpenting adalah bagaimana mengonsepkan bahasa warna dibandingkan dengan memahami bahasa lainnya. Semua teori warna dalam pengertiannya adalah termasuk teori bahasa, dan bagaimana "bicara”, "dengar", atau "baca”, warna banyak menjelaskan tentang bagaimana mengerti dunia.

Keilmuan Desain Komunikasi Visual mengacu pada eksperimen warna Johannes Itten (18881967). Itten seorang pelukis ekspresionis Swiss dan pengajar di sekolah Bauhaus, Weimar, Jerman. Bauhaus merupakan sekolah di Jerman yang mengombinasi kerajinan dan seni. Itten terkenal dengan pendekatan pada desain yang dipublikasikan dan diajarkan. Itten mengembangkan metodologi untuk mengoordinasikan warna dengan memanfaatkan sifat dan kontras warna. Johannes Itten adalah salah satu orang pertama yang mendefinisikan dan mengidentifikasikan strategi untuk kombinasi warna.

Nilai kontras dalam sebuah desain membangun suatu bentuk yang khas. Nilai kontras yang berubah secara bertahap adalah sebuah ilusi yang digunakan untuk membuat lengkungan dan kerangka bentuk yang terjadi dalam irama pengulangan (Wong, 1997). Gambar 2 menunjukkan terang gelap yang memberikan kesan dimensi dan kedalaman pada sebuah gambar. Untuk membentuk suatu objek, tidak diperlukan garis tepi sebagai kerangka objek tetapi menggunakan irama pengulangan.

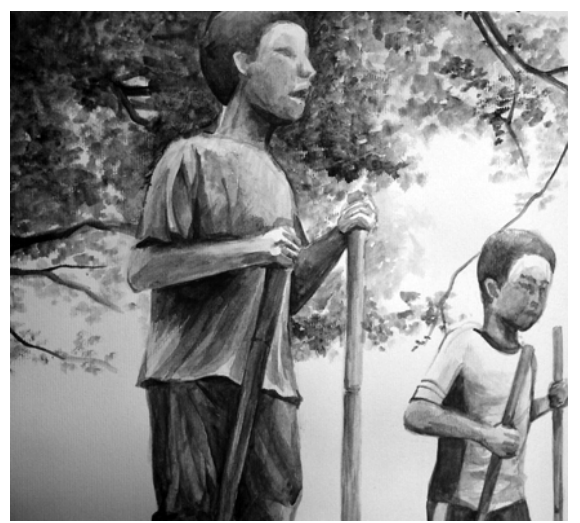

Gambar 2 Nilai Kontras dalam Suatu Desain (Sumber: M. Dzikri Gandara (mahasiswa DKV Binus))

Warna-warna khusus memiliki asosiasi dan efek emosional yang berbeda, mengakibatkan dimensi warna (nilai, intentistas, dan temperatur), memberikan efek berbeda bagi orang yang melihatnya. Memberikan kontras dalam nilai (value) menghasilkan efek presisi dan objektivitas. Misalnya putih, di Eropa bisa berarti kebahagiaan dan perayaan, sementara di China justru berarti kematian atau duka. Di antara berbagai budaya yang berbeda, beberapa warna dasar di waktu yang berbeda dapat memiliki arti/makna yang berlawanan (Feisner, 2000).

Mata secara alami mengenali kontras dan warna, khususnya warna yang ditemukan dalam spektrum pelangi (mejikuhibiniu = merah, jingga, kuning, hijau, biru, nila, ungu). Persepsi terhadap warna lainnya membutuhkan pemikiran lebih dalam lagi untuk mengenalinya. Karena manusia tidak mampu melihat semua kemungkinan warna, persepsi warna ditimbulkan oleh gelombang cahaya spektral yang dominan. Hal itu adalah alasan penyebab mata hampir selalu tertarik dengan hal yang mudah diterimanya (Stone, Adams \& Morioka, 2008). 


\section{Pengategorian Kebudayaan}

Pengategorian kebudayaan Indonesia yang beragam ini dilakukan untuk memudahkan peneliti memilah-milah penggunaan warna khas dari tiap wilayah. Adapun pengategorian tersebut adalah Seni Tari, Seni Rupa, Seni Pertunjukan/Panggung, Seni Musik. Jakarta; Seni Tari: tari Yapong, tari Topeng; Seni Musik: Rebana, Gambus, Kroncong Tugu, Gambang Kromong, Qasidah; Seni Rupa: makanan (jajanan pasar, bir pletok, dll), arsitektur, tekstil (batik, baju adat: pengantin, tarian, pengiring musik); Seni Pertunjukan/Panggung: ondel-ondel, wayang, lenong. Bandung; Seni Tari: tari Merak, tari Jaipongan; Seni Rupa: arsitektur (rumah panggung), tekstil (batik, baju adat: pengantin, tarian, pengiring musik); Seni Musik: degung, calung, angklung; Seni Pertunjukan/Panggung: wayang golek, reog. Yogyakarta; Seni Tari: Jathilan, Angguk, Serimpi, Golek Asmorodono, Topeng, Ramayana; Seni Rupa: arsitektur (joglo), makanan (gudek); Seni Musik: gamelan; Seni Pertunjukan/Panggung: wayang, kethoprak, karawitan. Semarang; Seni Tari: Semarangan, Lilin; Seni Rupa: makanan (lumpia, bandeng), arsitektur (joglo), batik; Seni Musik: Gambang Semarangan; Seni Pertunjukan/Panggung: wayang, kethoprak. Surabaya; Seni Tari: Remo, Lenggang; Seni Rupa: makanan (rawon, rujak cingur, leker, tahu tek); Seni Musik: gending jula juli, kentrung; Seni Pertunjukan/Panggung: reog, ludruk.

\section{Skema Warna}

Data berupa visual warna kebudayaan dari tiap daerah/wilayah dikomposisikan sedemikian rupa sehingga terbentuklah skema warna (10 warna) tiap daerah. Skema warna ini diperoleh dari dominasi warna yang tampil pada komposisi gambar. Selain komposisi warna, skema warna juga merujuk pada penulisan Darmaprawira (2002) mengenai warna di beberapa wilayah Indonesia.

\section{Jakarta}

Skema warna Jakarta didominasi warna-warna pada kebudayaan masyarakat Jakarta, yaitu Betawi. Hal ini dapat dilihat setiap hari ulang tahun Jakarta, warna-warni cerah memeriahkan pesta tersebut. Warna jambon (merah muda terang) merupakan warna yang paling banyak dijumpai disetiap kemeriahan acara masyarakat Betawi. Warna dadu (merah), hijau, kuning, jingga, dan biru juga menjadi warna Jakarta. Warna-warna cerah ini juga dapat ditemui di beberapa upacara adat masyarakat Betawi seperti: pernikahan dan sunatan. Pakaian pengantin dan para pengiringnya sudah dapat dipastikan berwarna terang dan cerah. Begitu pula baju para penarinya. Tidak ketinggalan jajanan pasar yang tersaji memiliki warna yang memikat dan membangkitkan selera makan. Kembang kelapa berwarna-warni penambah kemeriahan dan semaraknya acara saat itu. Ondel-ondel pun tidak mau ketinggalan dengan penampilannya berpakaian warna cerah dan memikat.

Warna-warna Betawi banyak dipengaruhi kebudayaan Cina, yang menyukai warna merah dan cerah. Komposisi penggunaan warna Betawi tanpa format (acak) tanpa ketentuan yang pasti. Warnawarna cerah ini tidak hanya menceritakan suasana suka cita tetapi juga semangat dan ketegasan masyarakat Betawi dalam menjalani kehidupan.
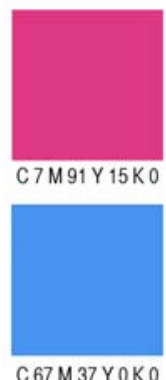

C 67 M 37 Y OKO
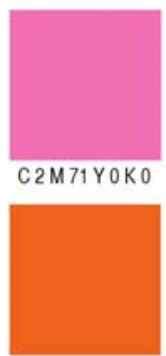

$\mathrm{C} 2 \mathrm{M} 76 \mathrm{Y} 100 \mathrm{KO}$

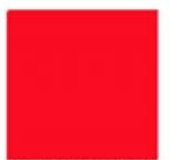

C 0 M 99 Y 96 Ko

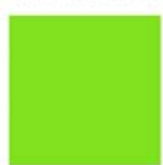

C $51 \mathrm{MOY} 100 \mathrm{KO}$

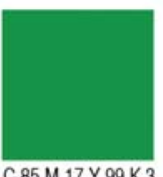

C $85 \mathrm{M} 17$ Y $99 \mathrm{~K} 3$

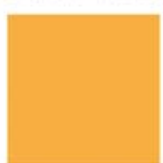

C 2 M 35 Y $85 \mathrm{KO}$
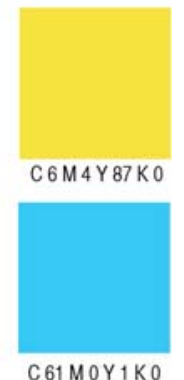

Gambar 3 Skema Warna Jakarta (format CMYK) 


\section{Bandung}

Skema warna Bandung (pesisir utara Jawa, meliputi Cirebon, Pekalongan, Tasikmalaya) hampir sama dengan warna Jakarta. Menggunakan warna-warna cerah dan terang. Namun karena banyak mendapatkan pengaruh dari Eropa melalui jalur pantai, warna masyarakat Sunda lebih muda dan beragam. Masyarakat Sunda mengenal hijau pupus (hijau muda), toska (hijau kebiruan), biru keunguan, dan merah muda. Warna-warna ini terlihat lebih "genit" dan menggoda dibandingkan dengan warna Betawi.

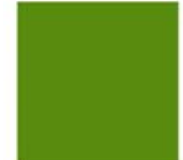

C $70 \mathrm{M} 25 \mathrm{Y} 100 \mathrm{~K} 9$

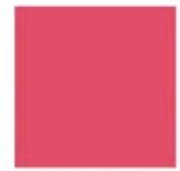

C 7 M 84 Y 46 KO

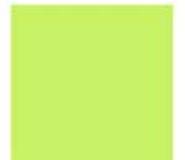

C $25 \mathrm{MOY} 76 \mathrm{KO}$

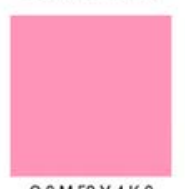

COM 53 Y $4 K 0$

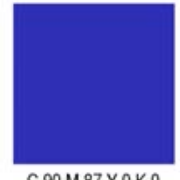

C $90 \mathrm{M} 87$ Y OKO

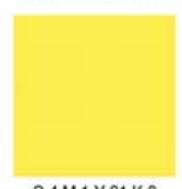

C $4 M 1 Y 81 K 0$

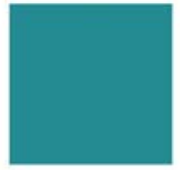

C $81 \mathrm{M} 29 \mathrm{Y} 41 \mathrm{~K} 3$

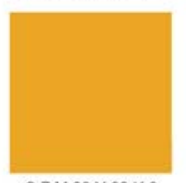

C7 738 Y $99 \mathrm{KO}$
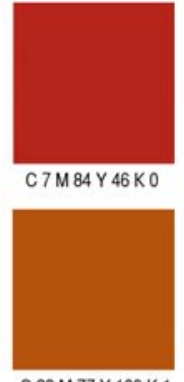

$22 \mathrm{M} 77 \mathrm{Y} 100 \mathrm{~K} 1$

Gambar 4 Skema Warna Bandung (format CMYK)

\section{Yogyakarta}

Skema warna Yogyakarta didominasi oleh berbagai macam warna coklat (sogan). Beberapa aksen hijau, coklat muda, dan biru dalu juga menyemarakkan skema warna Yogyakarta. Warna coklat banyak ditemui di artefak-artefak (batik, wayang, makanan) karena memang sumber warna utama pada kehidupan masyarakat Yogyakarta adalah buah sogan (warna keraton, warna raja). Warna Yogyakarta tidak mengenal hitam, tetapi biru dalu (biru tua/indigo).
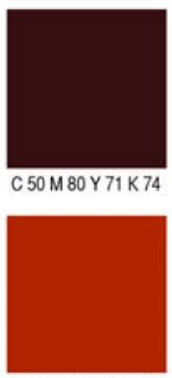

C 21 M 96 Y 100 K 14

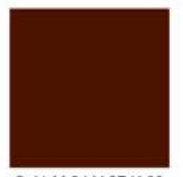

C $41 \mathrm{M} 84$ Y 87 K 66

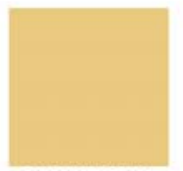

C $9 M 19$ Y 59 KO

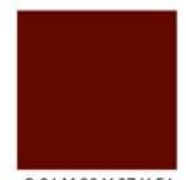

C $34 \mathrm{M} 96$ Y 97 K 54

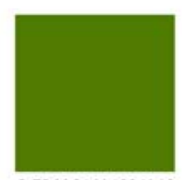

C 72 M 31 Y 100 K 16

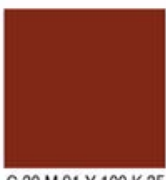

C $30 \mathrm{M} 91$ Y $100 \mathrm{~K} 35$

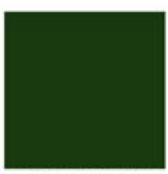

C $78 \mathrm{M} 49$ Y $93 \mathrm{~K} 6$
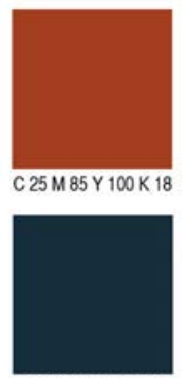

C $90 \mathrm{M} 70$ Y $53 \mathrm{~K} 54$

Gambar 5 Skema Warna Yogyakarta (format CMYK)

\section{Semarang}

Skema warna Semarang hampir sama dengan Yogyakarta (dominasi coklat), tetapi variasi coklatnya berbeda, lebih banyak didominasi coklat kekuningan. Hal ini dapat ditemui di beberapa kuliner dan tekstilnya. Beberapa warna cerah juga mudah ditemui (merah, pink, kuning, dan hijau). Hal ini dimungkinkan oleh terbukanya wilayah Semarang dari pendatang/wisatawan. 


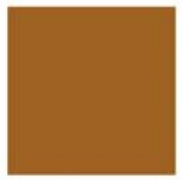

C $30 \mathrm{M} 62 \mathrm{Y} 100 \mathrm{~K} 18$

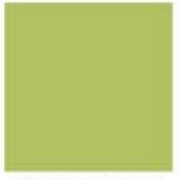

C $34 \mathrm{M} 11$ Y $78 \mathrm{KO}$

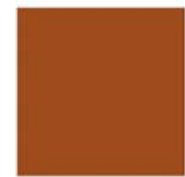

C 27 M 76 Y 100 K 200

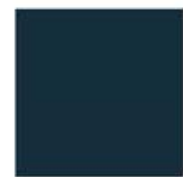

C $90 \mathrm{M} 70$ Y $53 \mathrm{~K} 54$

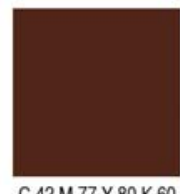

C $42 \mathrm{M} 77$ Y $80 \mathrm{~K} 60$

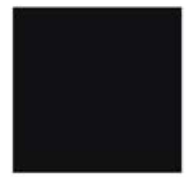

C 74 M 68 Y 64 K 81
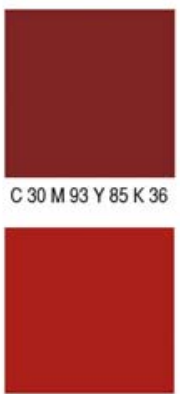

C 23 M 99 Y 100 K 16
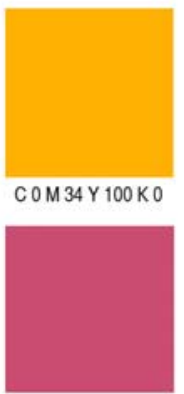

C $18 \mathrm{M} 85 Y 38 \mathrm{~K} 1$

Gambar 6 Skema Warna Semarang (format CMYK)

\section{Surabaya}

Skema warna Surabaya berbeda dengan dengan Yogyakarta meskipun pada dasarnya masih bernuansa coklat. Pengaruh budaya Madura sangat kuat pada kebudayaan Surabaya. Surabaya mengenal hitam dan merah. Hal ini dapat dilihat dari beberapa item kebudayaannya, seperti pada wayang, reog, dan tekstil (batik).
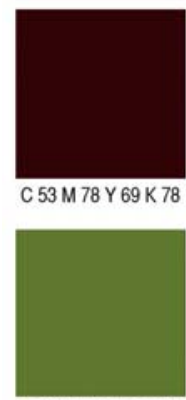

C 65 M 34 Y $100 \mathrm{~K} 18$
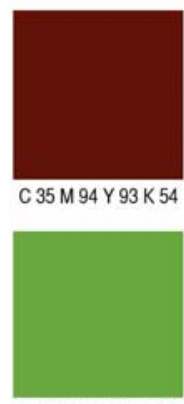

C $65 \mathrm{M} 13 \mathrm{Y} 100 \mathrm{~K} 1$
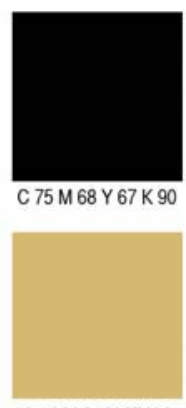

C $18 \mathrm{M} 24 \mathrm{Y} 67 \mathrm{KO}$
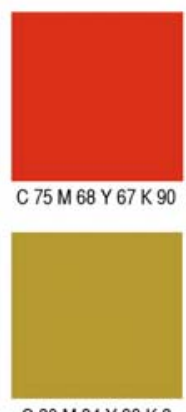

C $30 \mathrm{M} 34 \mathrm{Y} 99 \mathrm{~K} 3$
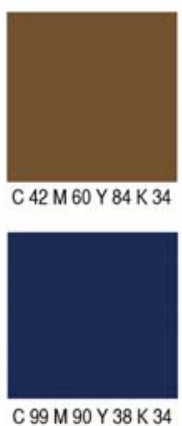

Gambar 7 Skema Warna Surabaya (format CMYK)

\section{Aplikasi Warna Baru}

Skema warna dari 5 kota besar di pulau Jawa diterapkan pada kemasan makanan atau minuman. Mahasiswa diminta untuk mengubah komposisi warna kemasan makanan atau minuman tersebut menjadi nuansa Jakarta, Bandung, Semarang, Yogyakarta, dan Surabaya. Proses pengaplikasian ini masih dalam tahap sketsa warna, belum final. Meskipun demikian, beberapa sketsa sudah mendekati nuansa yang diinginkan. Hasil aplikasi warna baru dari mahasiswa dapat dilihat pada halaman lampiran.

\section{SIMPULAN}

Mengetahui skema warna tiap daerah di Indonesia, secara khusus pulau Jawa dalam penelitian ini, dapat membantu para mahasiswa dalam penerapan ke media komunikasi visual lainnya selain kemasan, seperti logo, company profile, publishing (buku), dan sebagainya. Sementara itu untuk masyarakat luas pengguna warna (arsitek, desainer interior, fashion, pelukis), skema warna ini dapat menjadi modul warna dasar dalam menciptakan suasana (mood) suatu objek. Untuk bidang interior 
skema warna daerah dapat membantu desainer interior menciptakan suatu suasana daerah tertentu sesuai dengan yang diinginkan pada suatu ruangan, sehingga local content dapat dibentuk. Bagi masyarakat luas, skema warna ini bukan sekadar pengetahuan baru bagi mereka, melainkan dapat melahirkan cinta Indonesia dan cinta budaya daerah. Sehingga rasa bangga sebagai bagian dari negeri ini dapat dibangun guna pelestarian budaya dan citra bangsa.

Pengetahuan yang cukup akan suatu budaya melalui penerapan embian yang sesuai, sebaiknya dipahami dan dimiliki oleh pengguna warna dalam usahanya membangun suatu citra local content melalui media komunikasi visual. Sehingga pengguna tidak hanya menikmati hasil karya pilihannya tetapi juga bangga akan kekayaan warna budaya bangsanya. Penelitian diharapkan dapat berlanjut ke kota-kota besar lain di Indonesia yang dapat mewakili daerah-daerah tertentu. Dengan demikian ciri khas warna dari tiap kebudayaan di Indonesia dapat diperoleh.

\section{DAFTAR PUSTAKA}

Darmaprawira, S. (2002). Warna: Teori dan Kreativitas Penggunaannya. Bandung: ITB.

Feisner, E. A. (2000). Colour: How to Use Colour in Art and Design. London: Laurence King.

Fraser, T., \& Adam Banks. (2004). The Complete Guide to Color. United Kingdom: Ilex Press.

Stone, T. L., Adams, S., \& Morioka, N. (2008). Color Design Workbook: a Real-World Guide to Using Color in Graphic Design. London: Rockport.

Van Hagen, E. (1970). Itten, The Element of Color. New York, Cincinnati, Toronto, London, Melbourne: Van Nostrand Reinhold. 


\section{LAMPIRAN}

\section{Jakarta:}

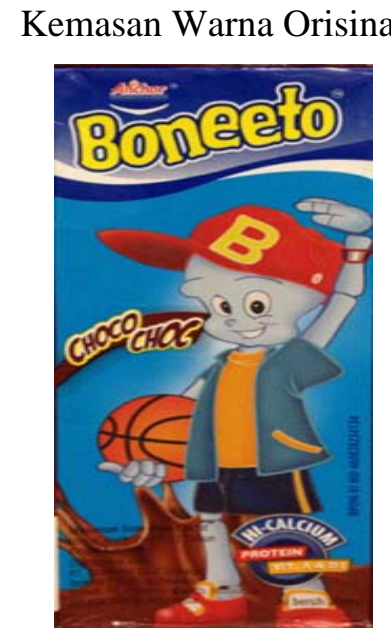

Kemasan Warna Baru

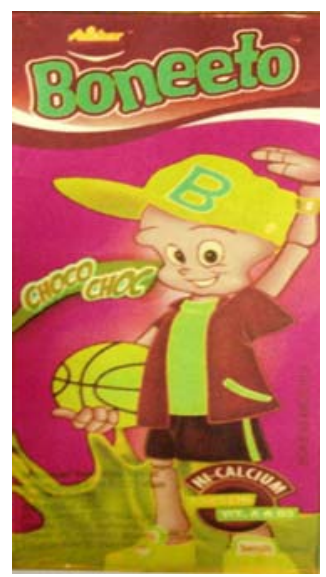

Kemasan Warna Orisinal

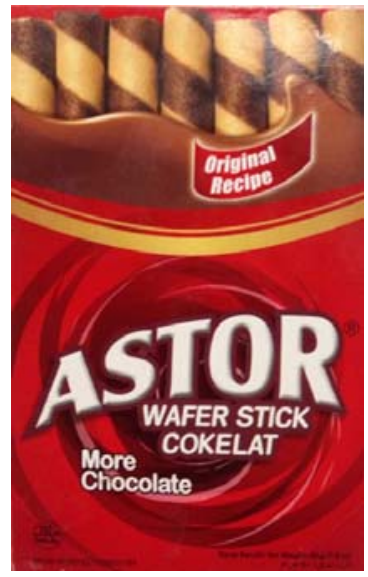

Kemasan Warna Baru
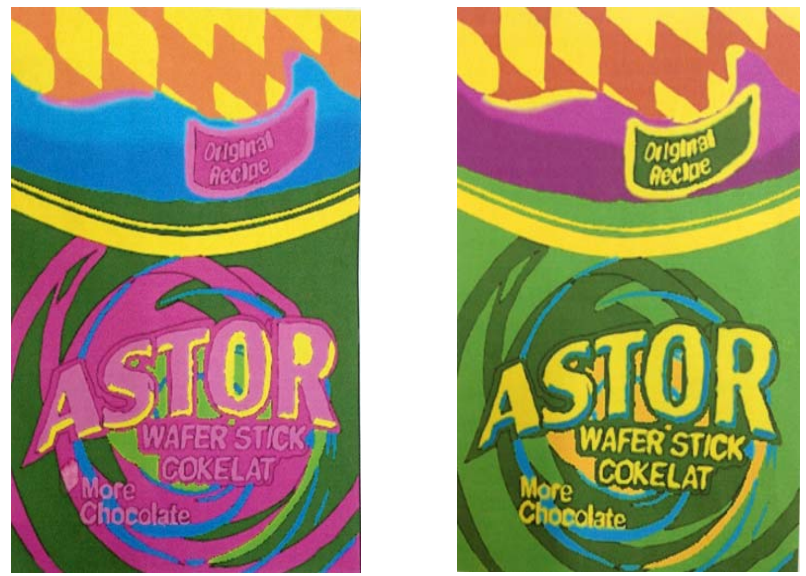

\section{Bandung:}

Kemasan Warna Orisinal

Kemasan Warna Baru
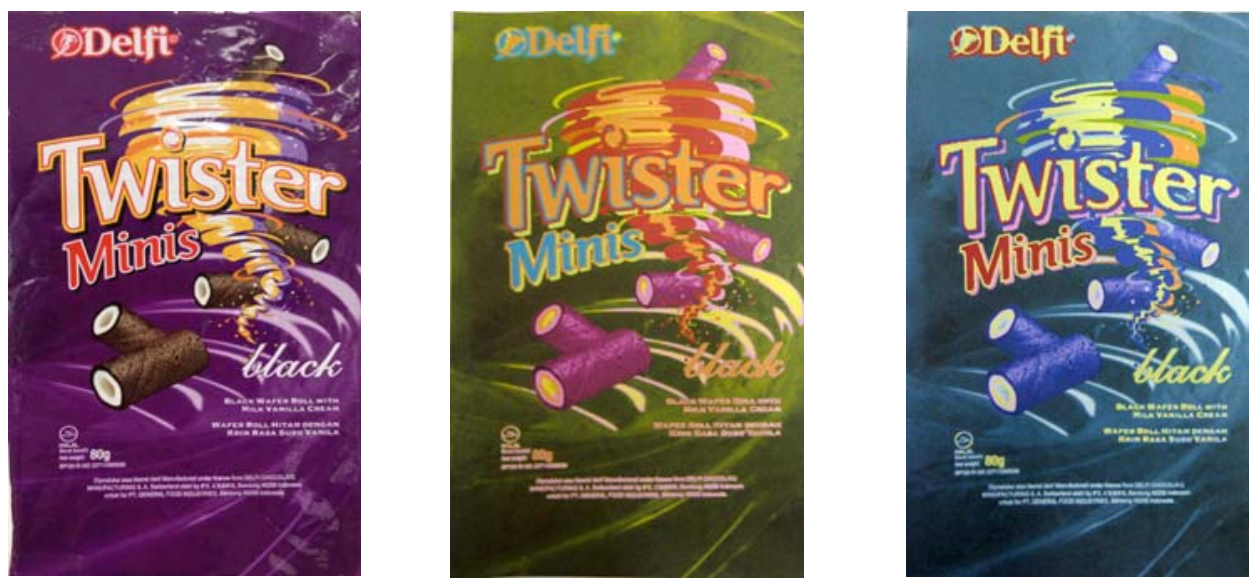
Kemasan Warna Orisinal

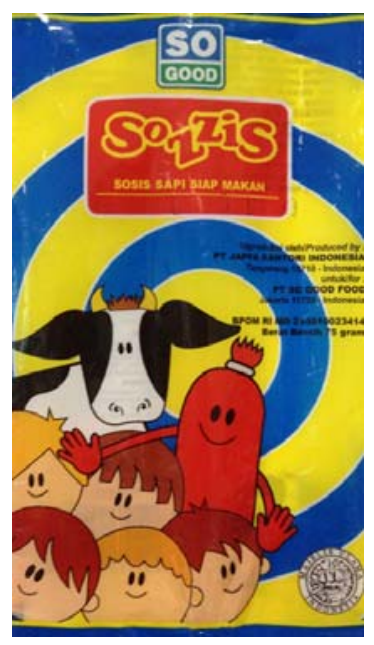

Kemasan Warna Baru

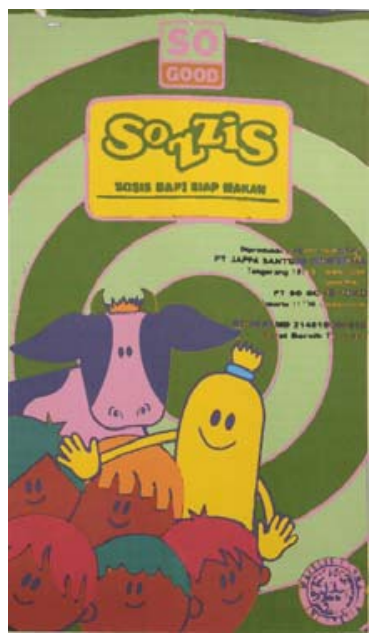

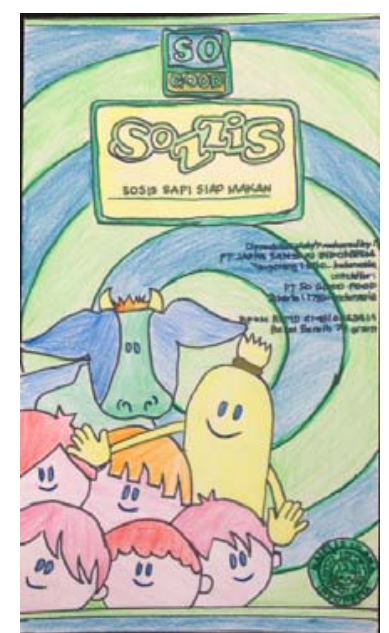

\section{Yogyakarta:}

Kemasan Warna Orisinal

Kemasan Warna Baru
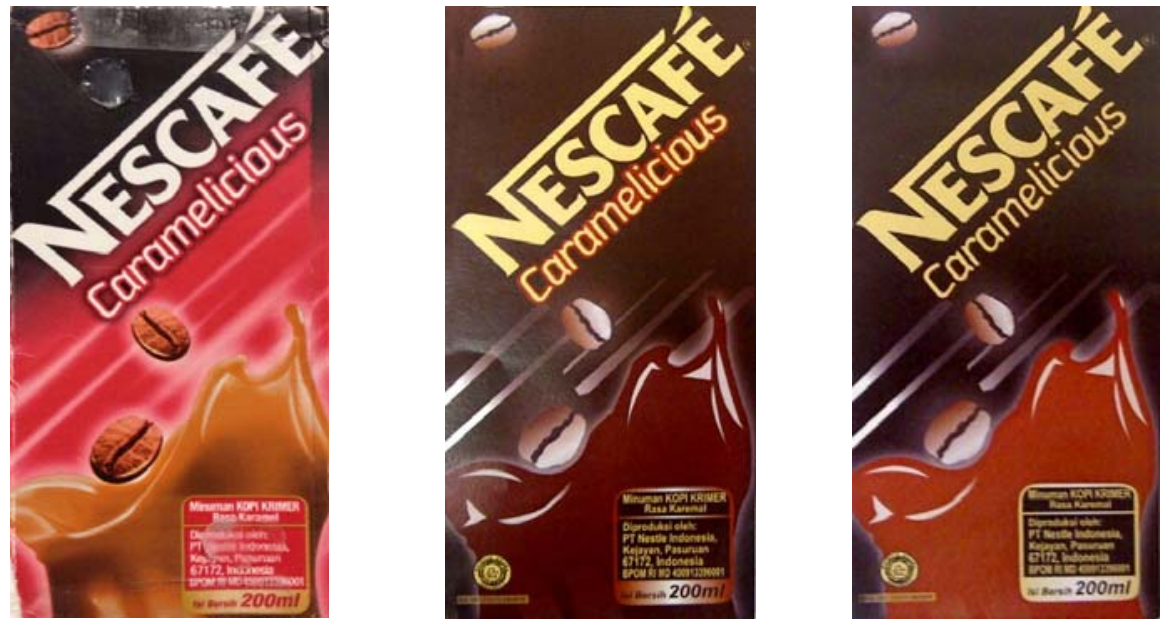

Kemasan Warna Orisinal

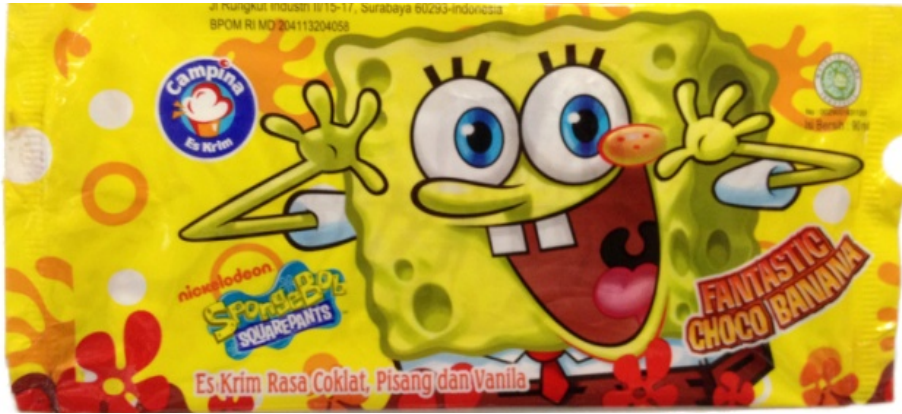


Kemasan Warna Baru
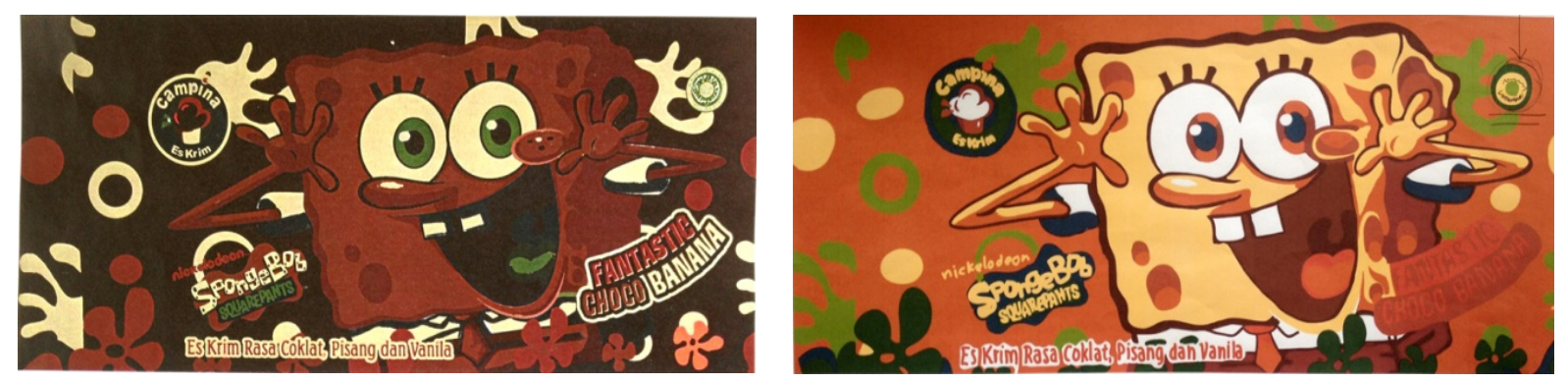

\section{Semarang:}

Kemasan Warna Orisinal

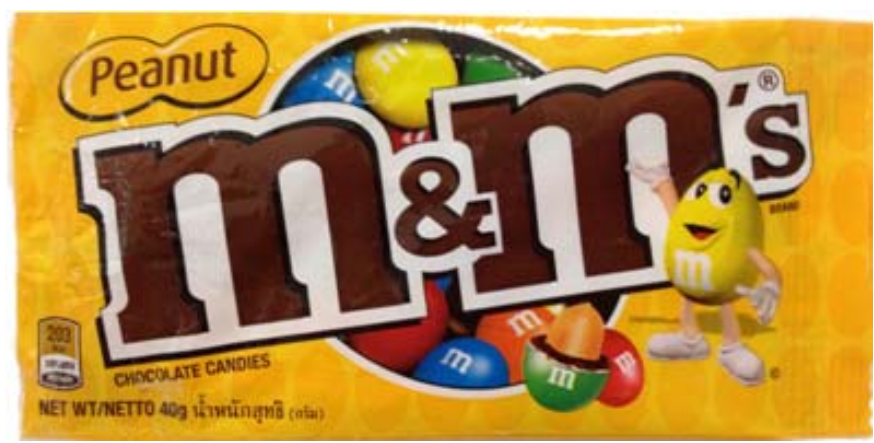

Kemasan Warna Baru
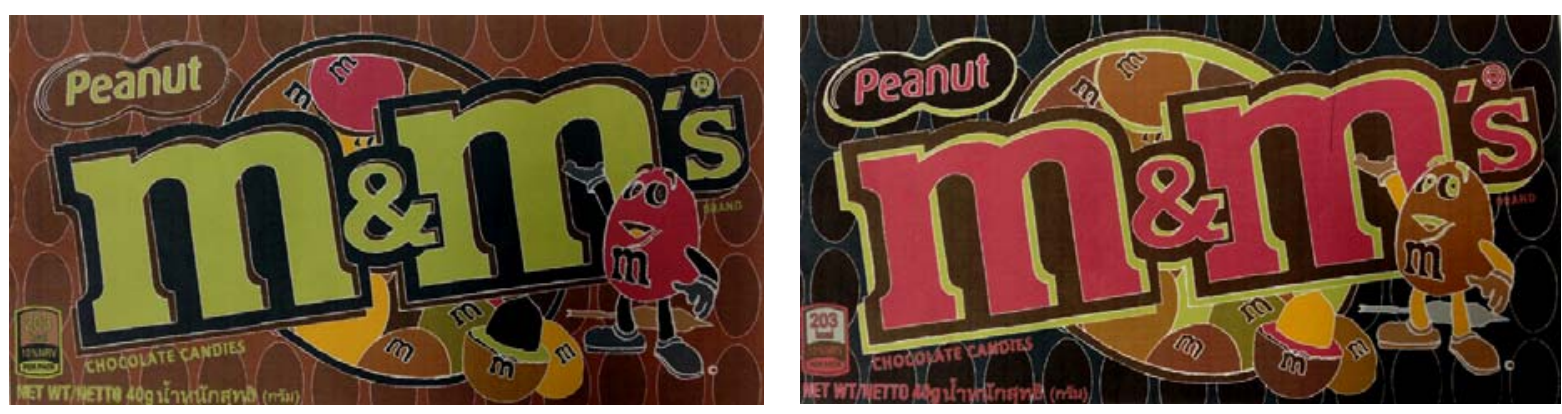

Kemasan Warna Orisinal

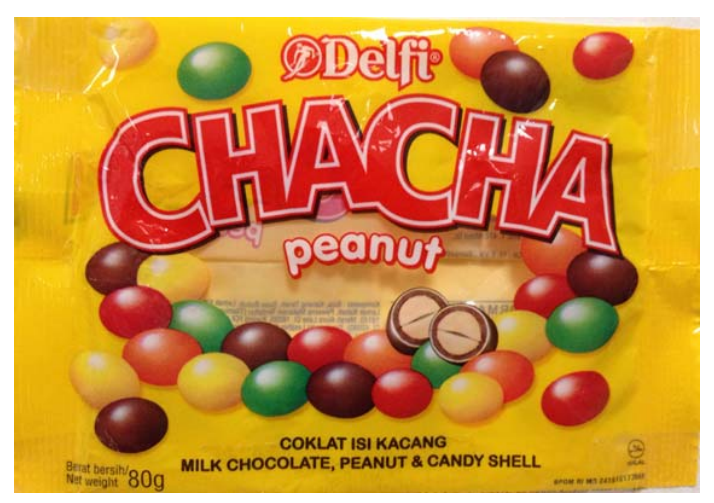

Kemasan Warna Baru

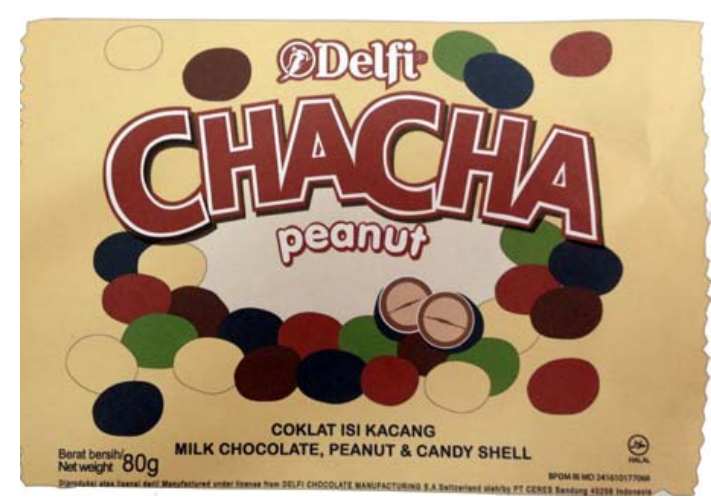


Kemasan Warna Orisinal

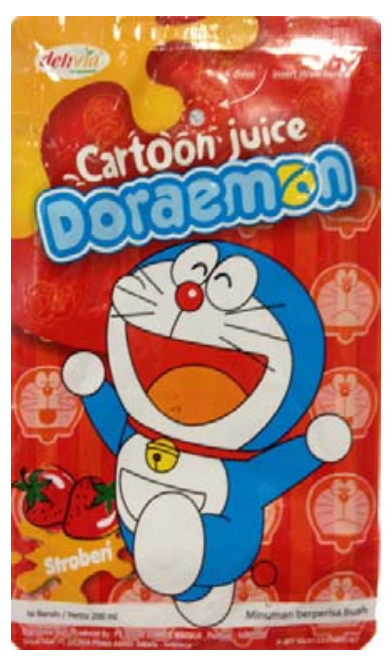

Kemasan Warna Baru

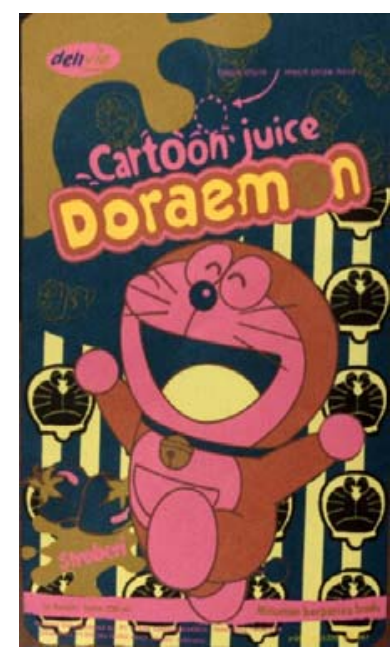

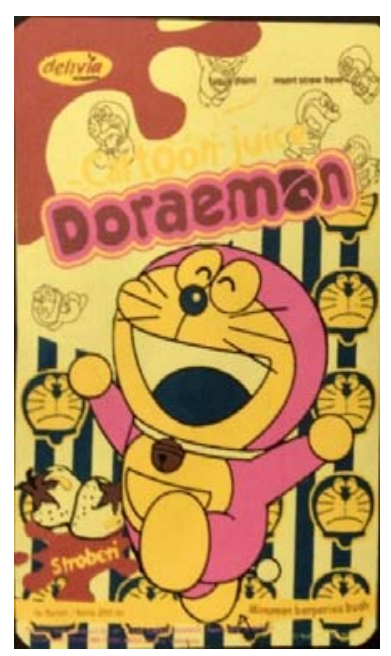

\section{Surabaya:}

Kemasan Warna Orisinal

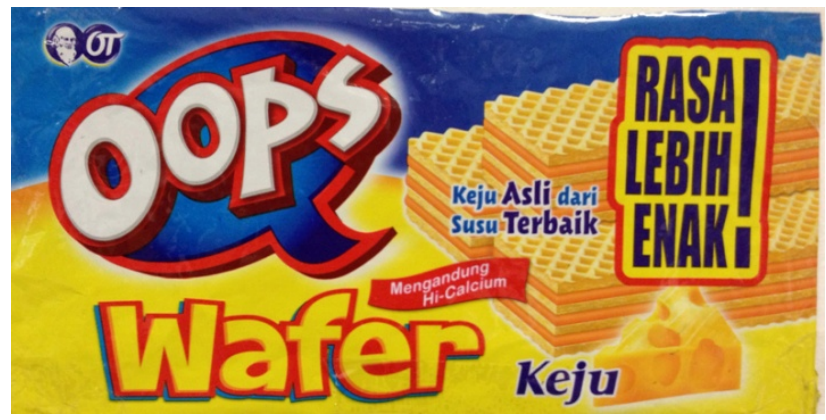

Kemasan Warna Baru
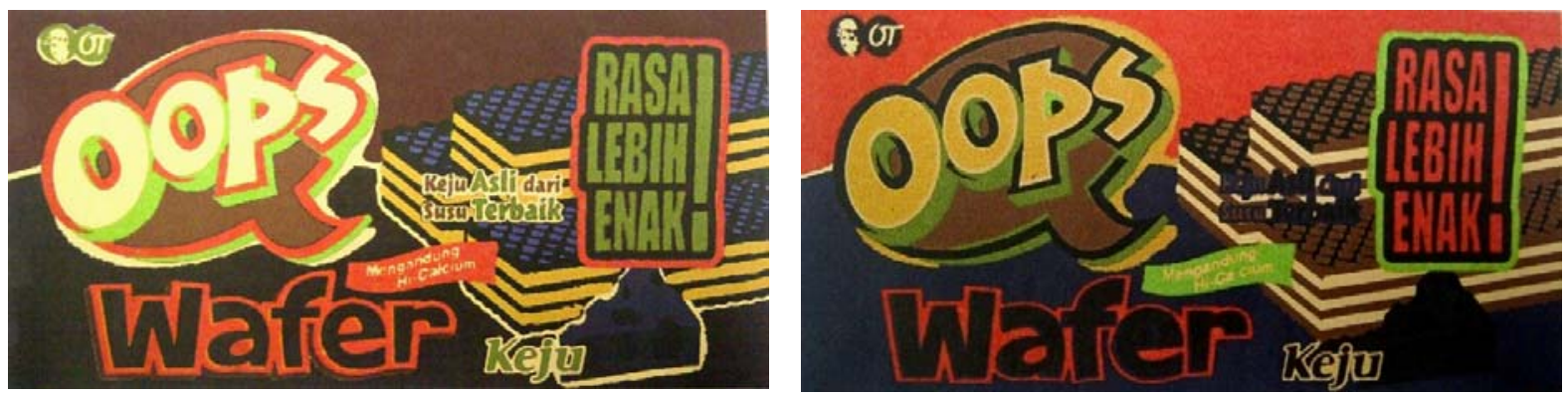